
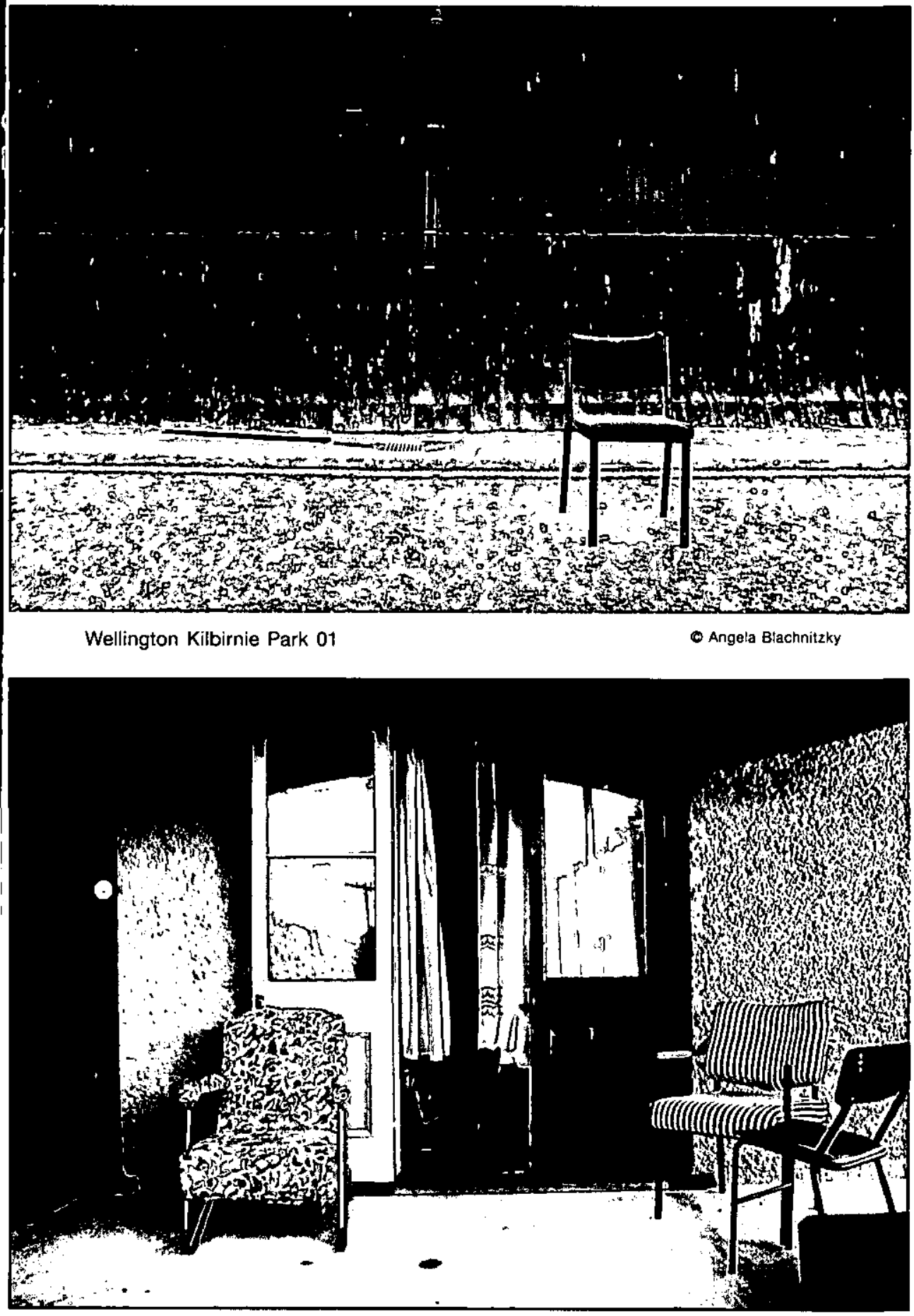


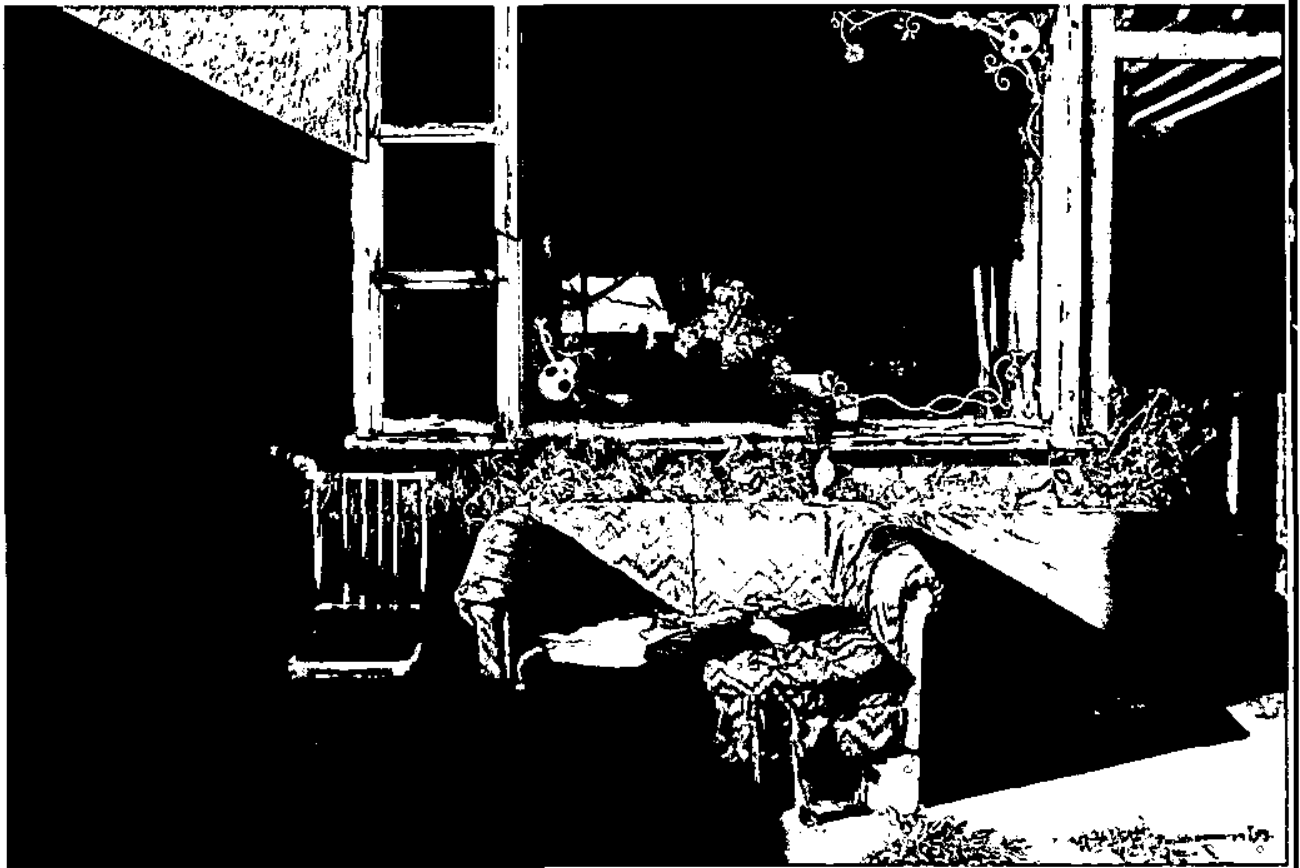

Wellington Oriental Bay 01

Angela Blachnitzky

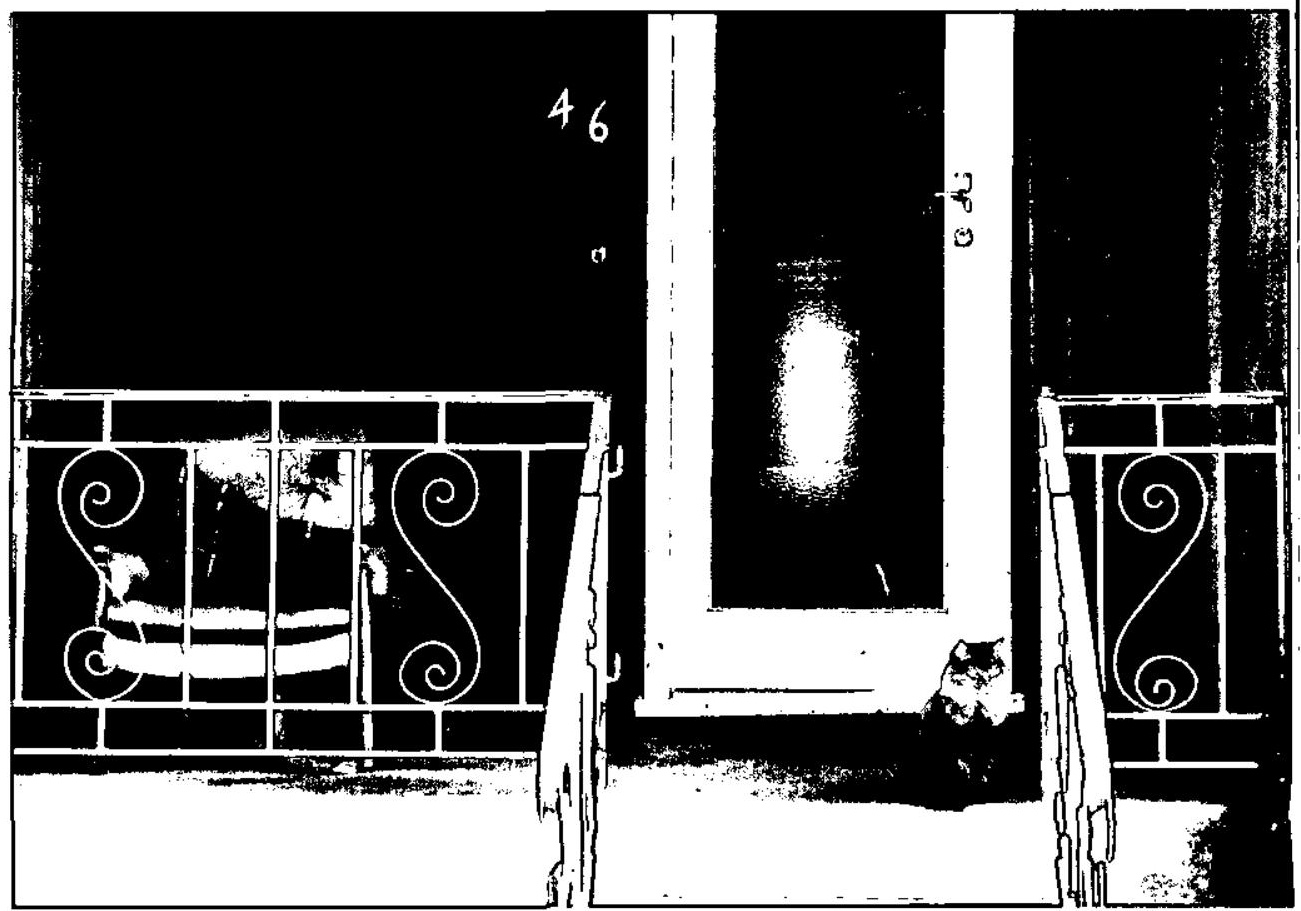




\section{Outside Culture}

ANGELA BLACHNITZKY

\section{About the project}

The cover on this issue of the Journal is one example out of a recent project on 'outside culture'. My photographic documentary portrays interior furniture abnormally situated in an outside location. Often placed in front of houses or in gardens, the chairs and couches beckon the viewer to come and sit down, to relax in a 'homely atmosphere.' When placing furniture items outside, the context gets altered. The boundaries of the interior and the exterior become blurred, giving the works a surreal aesthetic.

Taking interior furniture outside, especially in summer, is a familiar custom in New Zealand but not worldwide. In Germany only homeless people who live under bridges would put interior furniture outside. When coming to Wellington, I thought it was a strange habit, worth documenting. When I questioned why people place their furniture outside the reasons given vary. Some people cannot afford to buy outdoor furniture (such as students), others put their sofas outside when they become too scruffy and do not know where else to store them. Some just prefer the comfort of upholstered furniture.

The quirky characteristics of this relocated furniture are connected to the way the furniture begins to break down where the effects of wind, rain and extreme sun take their toll. The elements fill the furniture with a certain rustic charm, as they acquire an intriguing characteristic all of their own.

'Outside culture' is an ongoing project. I appreciate any input as to where l could document more of this Kiwi ethos. If you know of a location, please submit it via my website www.outside-culture.co.nz

In 2009 I am planning a tour around New Zealand in order to investigate current customs through a photographic survey and interviews. I am also planning to publish the book "outside culture" after a suitable publisher has been found.

\section{About the artist}

Angela Blachnitzky was born in Munich, Germany in 1971. She graduated from the University of Design in Schwäbisch Gmünd, Germany in 1996. From 1996 to 2001 she headed the German web-design department of Cable \& Wireless, an international telecommunication company, and in 
2004 she founded the German design office Gestaltungsland. From 2001 to 2006 Angela was a part-time lecturer for multimedia design basics, usability, animation, webdesign and layout at the University of Applied Sciences in Munich, Germany. She moved to New Zealand in 2006. Since January 2007 she has been employed at Victoria University of Wellington as a lecturer in the School of Design. In her spare time, Angela works on independent art projects. More of her work can be found at www.blachnitzky.co.nz 